\title{
Comment to the article: Wise J. Five priorities of care for dying people replace Liverpool care pathway
}

\author{
Massimo Costantini, Silvia Di Leo \\ Palliative Care Unit, IRCCS Arcispedale S. Maria Nuova, Reggio Emilia, Italy
}

There is an international agreement about the importance of providing the best palliative care for cancer patients dying in hospital and their families. ${ }^{1}$ Conversely, surveys performed in many countries show that cancer patients in hospital suffer from unrelieved and poor treated physical symptoms, and from emotional and spiritual distress., ${ }^{2,3}$ Also most family members do not receive an appropriate support and an effective communication before and after the patient's death. ${ }^{3}$

Care pathways for dying patients have been developed and piloted in several countries as a model to improve the quality of care at the end of life in hospital and in other settings of care. ${ }^{4,5}$ The Liverpool care pathway (LCP) is an integrated care pathway developed by Royal Liverpool University Hospital and Liverpool's Marie Curie Hospice (UK) in the late 1990s to transfer the model of excellence for care of the dying from hospices to hospitals. ${ }^{5,6}$ The pathway provides a template of appropriate, evidence-based, multidisciplinary care of the dying, designed to replace all other documentation at the end of life..$^{5,6}$ The original LCP clinical documentation is focused on the different dimensions of end of life care, including physical comfort, anticipatory prescribing of medication and discontinuation of inappropriate treatments, as well as psychological and spiritual care. Besides, the pathway includes goals that deal with the care of the family before and after the patient's death.

Correspondence: Massimo Costantini, Palliative Care Unit, IRCCS Arcispedale S. Maria Nuova, viale Umberto I 50, 42123 Reggio Emilia, Italy.

Tel.: +39.0522.295369 - Fax: +39.0522.295622.

E-mail: Massimo.Costantini@asmn.re.it

Key words: Liverpool care pathway, comment, palliative care.

Received for publication: 17 July 2014.

Accepted for publication: 17 July 2014.

This work is licensed under a Creative Commons Attribution NonCommercial 3.0 License (CC BY-NC 3.0).

CCopyright M. Costantini and S. Di Leo, 2014

Licensee PAGEPress, Italy

Italian Journal of Medicine 2014; 8:265-267

doi:10.4081/itjm.2014.538
The LCP became very popular in UK and abroad. In 2011, the pathway was used by two-third of UK hospitals and it was translated, adapted and implemented in over 20 countries, including Italy. The widespread dissemination of the LCP highlights the demand for interventions that could reduce the gap between inpatient hospices and hospital wards in the quality of care at the end of life.

The initial reception from professionals and the media was positive, but in 2009 and 2012 the media reported a number of cases of malpractice associated with LCP use in hospitals. As a consequence, the Ministry of Health appointed an independent panel to review the use and experience of the LCP in England. In this review, ${ }^{7}$ the panel concluded that when the LCP is used properly, it delivers good end-of-life care. Nevertheless, the implementation of the pathway was found to be lacking, and it was often conceived as a tick box exercise. Many decisions were taken in ward settings without the oversight of an experienced physician. Often neither patients nor family were informed about the clinical worsening of the patient and consulted and involved in the changed plan of care. The report specifies that generic protocols (as the LCP is regarded) are not the right approach to the care of the dying, and that care should be individualized according to the needs and preferences of the dying person and those who are important for them. Consequently, the review recommended that the LCP should be phased out over 6-12 months. The next step was the establishment of a coalition of 21 national organizations, the Leadership Alliance for the Care of Dying People (LACDP), with the aim of developing policies and processes for ensuring high quality, consistent care for people in the last days and hours of life.

The LACPD recently developed a document One chance to get it right ${ }^{8}$ (summarized by Wise ${ }^{9}$ ), presenting the new approach that should be adopted in future for caring dying people. The document was focused on five priorities for care: i) the possibility that a person should may die within the following few days or hours should be recognized and communicated clearly, decisions about care should be made in accordance with the person's needs and wishes, and these should be reviewed and revised regularly; ii) sensitive communication should take place between staff and the dying person and those important to them; iii) the dying person, and those identified as important to 
them, should be involved in decision about treatment and care; iv) the people important to the dying person should be listened to and their needs respected and met as far as possible; v) an individual plan of care, which includes food and drink, symptom control, and psychological, social, and spiritual support, should be agreed, coordinated, and delivered with compassion.

Within the document, the LACDP specifies that many healthcare professionals are already delivering good end-of-life care according to these priorities by using the LCP. Nevertheless, the document states that since ...the LCP was associated with standardised treatment and care, carried out irrespective of whether that was right for the particular person in particular circumstances [...], the risk of this continuing to happen is not tenable. ${ }^{8}$ The way in which these priorities are achieved should reflect the needs and preferences of the dying person, as well as the setting of care.

The story of the LCP is also Italian. In 2007, the Italian hospital version of the LCP program was developed by the Ligurian Palliative Care Network of Genoa, the referent center for the LCP in Italy, in compliance with the original format. The Italian version of the pathway (LCP-I) was successfully piloted within 4 hospital wards of Genoa following the original 10 steps continuous quality improvement program. ${ }^{10-12}$ One year after, a further project was developed aimed at assessing and piloting the LCP program within the hospice setting. ${ }^{13}$ The results of these studies were positive, and supported the design of a cluster randomized phase III study. This study was aimed at assessing the effectiveness of the program in improving the quality of end-of-life care for patients with cancer dying in Italian hospitals. ${ }^{14}$

Findings from this trial ${ }^{15}$ were smaller than those of the previous phase II study, ${ }^{12}$ and did not reach significance for the primary outcome, although some secondary benefits were seen. These findings should be interpreted taking into account key factors featuring in the LCP-I hospital implementation program, which was highly standardized, with specific contents and duration, and a strictly planned support from the palliative care team implementing the pathway in the ward.

On the basis of current evidence on the pathway and of problems related to its dissemination in UK, members of the Italian LCP-I referent centre have been recently met professionals of most Italian hospital wards involved in the LCP implementation program, with the aim of sharing opinions and experiences about it. Over 50 professionals (physicians and nurses) from 20 structures of six Italian regions participated in the meeting. Both strengths and weaknesses concerning the use of the pathway were debated (Table 1), and a panel discussion has begun, focused on establishing which measures should be currently adopted at a national level. The purpose of enhancing the potential benefits of the LCP-I, as well as that of coping with the risks associated with its intrinsic limitations and inappropriate dissemination, were unanimously emphasized, regardless of any specific measure that will be taken in the future.

According to the discussion of the meeting, and taking into account what emerged from the international discussion, we decided to phase out the LCP in

Table 1. Strengths and weaknesses of the Liverpool care pathway program in hospital resulted from the Italian meeting.

\begin{tabular}{|c|c|}
\hline Strengths & Weaknesses \\
\hline - Specificity on the dying phase & - Problems in shared decision-making between professionals \\
\hline - Change of professionals' vision & - LCP as tick-box exercise \\
\hline - Inclusion of ethical issues into the clinical practice & - Deficit in training \\
\hline - Inclusion of spiritual issues into the clinical practice & - Problems in integrating LCP with the other clinical documentation \\
\hline - Better communication between professionals & - Problems in recognising the dying phase \\
\hline - Increased shared decision-making between professionals & \multirow{2}{*}{$\begin{array}{l}\text { - Problems in communicating with patients and relatives } \\
\text { (deficit of training) }\end{array}$} \\
\hline - Increased professional autonomy of nurses & \\
\hline - Improvement of communication with patients and relatives & - Ward areas not adequate \\
\hline - Improvement in symptoms management & - Lack of time - workload \\
\hline - Use of subcutaneous route & - Too short support from palliative care team \\
\hline - Decreasing of usefulness procedures & - Professionals' turnover \\
\hline \multirow{3}{*}{ - Increased palliative care consultations } & - Poor involvement of the hospital management \\
\hline & - Misinterpretation of the remodulation of the therapies \\
\hline & - Legal issues \\
\hline
\end{tabular}

LCP, Liverpool care pathway. 
Italy. The same decision is going to be taken, in the next months, in all countries where the LCP was disseminated. Unfortunately, the problem remains. The quality of care for the dying patients in hospital is still suboptimal. The data from the Italian phase III trial, ${ }^{15}$ contrasted with the results of a similar study performed in Italian hospices, estimated the magnitude of the gap in quality of care between hospitals and hospices. This gap should be bridged in some way.

The five priorities of care for dying people, ${ }^{8}$ developed in England in response to the Neuberger review, ${ }^{7}$ represent a possible way of constructively taking into account what we have learnt from the LCP. Since the principles informing these priorities are common to those informing the LCP, these are focused on the process over the outcome of care, highlighting the changing needs of patients and families both prior and during the dying phase. Any intervention, also stresses the document, should not only focused on the last hours-days of life, but more in general on the palliative care needs of the patient. For getting to a positive change, the role of palliative care team is paramount.

The Italian research agenda for the next years will be still centered on developing and assessing effective strategies for bridging this gap. Despite the multiple challenges featuring in end-of-life care, we have demonstrated to be able to perform high quality research in this field. We must go on with this policy.

\section{References}

1. [No authors listed]. End-of-life care: the neglected core business of medicine. Lancet 2012;379:1171.

2. Higginson IJ, Costantini M. Dying with cancer, living well with advanced cancer. Eur J Cancer 2008;44: 1414-24.

3. Beccaro M, Caraceni A, Costantini M. End-of-life care in Italian hospitals: quality and satisfaction of care from the caregivers' point of view. Results from the Italian Survey of Dying Cancer Patients (ISDOC). J Pain Symptom Manage 2010;39:1003-15.

4. Lo SH, Chan CY, Chan C-H, et al. The implementation of an end-of-life integrated care pathway in a Chinese population. Int J Palliat Nurs 2009;15:384-8.

5. Ellershaw J, Ward C. Care of the dying: the last hours or days of life. BMJ 2003;326:30-4.

6. Ellershaw J, Foster A, Murphy D, Shea T, Overill S. Developing an integrated care pathway for the dying patient. Eur J Palliat Care 1997;4:203-7.

7. UK Department of Health. Review of Liverpool Care Pathway for dying patients; 15 July 2013. Available from: https://www.gov.uk/government/publications/review-of-liverpool-care-pathway-for-dying-patients Accessed: 4 June 2014.

8. Leadership Alliance for the Care of Dying People (LACDP). One chance to get it right. Improving people's experience of care in the last days and hours of life; June 2014. Publications Gateway Reference 01509. Available from: https:/www.gov.uk/government/uploads/system/uploads/attachment_data/file/323188/One chance_to_get_it_right.pdf Accessed: 17 June 2014.

9. Wise J. Five priorities of care for dying people replace Liverpool care pathway. BMJ 2014;348:g4299.

10. Di Leo S, Beccaro M, Finelli S, et al. Expectations about and impact of the Liverpool Care Pathway for the dying patient in an Italian hospital. Palliat Med 2011;25: 293-303.

11. Costantini M, Di Leo S, Beccaro M. Methodological issues in a before-after study design to evaluate the Liverpool Care Pathway for the Dying Patient in hospital. Palliat Med 2011;25:766-73.

12. Costantini M, Pellegrini F, Di Leo S, et al. The Liverpool Care Pathway for cancer patients dying in hospital medical wards: a before-after cluster phase II trial of outcomes reported by family members. Palliat Med 2014;28:10-7.

13. Di Leo S, Bono L, Romoli V, et al. Implementation of the Liverpool Care Pathway for the Dying Patient (LCP) in the inpatient hospice setting: development and preliminary assessment of the Italian LCP programme. Am J Hosp Palliat Med 2014;31:61-8.

14. Costantini M, Ottonelli S, Canavacci L, et al. The effectiveness of the Liverpool Care Pathway in improving end of life care for dying cancer patients in hospital. A cluster randomised trial. BMC Health Serv Res 2011;11:13.

15. Costantini M, Romoli V, Di Leo S, et al. Liverpool Care Pathway for patients with cancer in hospital: a cluster randomised trial. Lancet 2014;383:226-37. 